NBER WORKING PAPER SERIES

\author{
SCHOOL RESOURCES AND STUDENT \\ OUTCOMES: AN OVERVIEW OF THE \\ LITERATURE AND NEW EVIDENCE FROM \\ NORTH AND SOUTH CAROLINA
}

David Card

Alan Krueger

NBER Working Paper 5708
NATIONAL BUREAU OF ECONOMIC RESEARCH
1050 Massachusetts Avenue
Cambridge, MA 02138
August 1996

This paper was funded in part by a grant from the National Institute of Child Health and Development. We thank Francine Blau, Brad De Long, and Tim Taylor for comments and suggestions on earlier drafts. This paper is part of NBER's research program in Labor Studies. Any opinions expressed are those of the authors and not those of the National Bureau of Economic Research.

(C) 1996 by David Card and Alan Krueger. All rights reserved. Short sections of text, not to exceed two paragraphs, may be quoted without explicit permission provided that full credit, including $\odot$ notice, is given to the source. 


\title{
SCHOOL RESOURCES AND STUDENT \\ OUTCOMES: AN OVERVIEW OF THE \\ LITERATURE AND NEW EVIDENCE FROM \\ NORTH AND SOUTH CAROLINA
}

\begin{abstract}
This paper reviews and interprets the literature on the effect of school resources on students' eventual earnings and educational attainment. In addition, new evidence is presented on the impact of the great disparity in school resources between black and white students in North and South Carolina that existed in the first half of the 20th century, and the subsequent narrowing of these resource disparities. Following birth cohorts over time, gaps in earnings and educational attainment for blacks and whites in the Carolinas tend to mirror the gaps in school resources.
\end{abstract}

David Card

Industrial Relations Section

Firestone Library

Princeton University

Princeton, NJ 08544

and NBER

decard@marlowe.princeton.edu

\author{
Alan Krueger \\ Woodrow Wilson School \\ Princeton University \\ Princeton, NJ 08544 \\ and NBER \\ akrueger@pucc.princeton.edu
}


Thirty years after the publication of the Coleman report (1966) marks a fitting time to reassess the connection between school resources and student achievement. Coleman's original study and much of the subsequent literature it spawned are widely interpreted as showing that higher levels of school resources, such as lower class sizes, have no effect on student test scores. For example, Hanushek's (1986) influential survey of the literature concluded, "There appears to be no strong or systematic relationship between school expenditures and student performance."

The conclusion that schooling inputs like class size and teacher pay have no impact on student achievement has come under renewed scrutiny for two main reasons. First, several recent meta-analyses -- quantitative summaries of the estimates in the literature -- suggest that greater resources do in fact lead to higher test scores. The authors of these studies argue that the literature contains too many positive estimates of the effect of resources on test scores to have occurred by chance, if resources truly do not matter. ${ }^{1}$ Observe, for example, that Hanushek (1996) counts more than twice as many positive than negative estimates of the effect of expenditures per pupil on student achievement, among the 141 "studies" that report their signs. If each estimate had a 50-50 chance of being positive or negative, the odds of observing so many positive estimates by chance is less than one in a million. ${ }^{2}$ Low power of the individual estimates may explain why the preponderance of studies find statistically insignificant effects, while the combined literature points in the opposite direction. Meta-analysis also provides methods for accounting for the magnitude of estimated effects in the literature, as well as their signs. Hedges, et al. (1994) conduct a metaanalysis of the studies surveyed by Hanushek (1986) and conclude that, "the data are more consistent with a pattern that includes at least some positive 
relation between dollars spent on education and output, than with a pattern of no effects or negative effects."

Second, and more germane to this paper, is a body of literature that shifts attention away from test scores and focuses instead on how school resources affect students' educational attainment and earnings. Studying the impact of school resources on long-term outcomes like educational attainment and earnings is critical because test scores are an imperfect measure of the value of school outputs. For example, Murnane, Levy and Willet (1995) find that adding a standardized mathematics test score to a wage equation for male workers increases the explanatory power of the model by only about 2 percentage points. Heckman (1995) concludes, "neither $\mathrm{g}$ [a measure of generalized intelligence] nor AFQT [the Armed Forces Qualifying Test] explains all that much of the variance in log wages." In sharp contrast to the literature on test scores, a number of studies have found a positive and statistically significant association between education resources and students' educational attainment and earnings.

Researchers face a number of obstacles in studying the connection between school resources and economic outcomes. One difficulty is the need to wait until students finish school and join the labor market. Consequently, researchers must have access to data sets that report both the current earnings or completed education of adults and information on the resources available in the schools they attended. Furthermore, since differences in the structure of the labor market may affect the reward to skills, and thus the measured impact of school resources, evaluations of the economic returns to school resources may require non-trivial identification assumptions, or complex econometric modelling, or both. Another problem is that compared to 
test score outcomes, the variance in earnings is large, making it more difficult to detect modest effects of school quality.

Omitted variables, such as parental background or state-level political variables, may bias the measured effect of school resources. (Of course, a parallel problem arises in non-experimental studies of the effect of school resources on test scores.) Since the children of wealthier parents often attend schools with smaller class sizes and better-paid teachers, and since family background is thought to exert an independent effect on children's economic outcomes, there may be a spurious positive association between school resources and measured outcomes, even if school resources have no effect per se. On the other hand, students with weaker backgrounds may be assigned to remedial classes with higher resources per student, inducing a spurious negative correlation between school resources and student outcomes.

A study of economic outcomes requires a theoretical framework that incorporates the diverse interactions between family background, school inputs, educational attainment, and earnings. We therefore begin this paper by outlining the key implications of such a model. This framework is then used to interpret estimates of the effect of school resources on educational attainment and earnings. Our reading of the empirical literature is that school resources tend to be positively associated with earnings and educational attainment, but that the relationship is not always robust to specific features of the data set or empirical specification.

A difficult problem for most studies in the literature, including our own, is the presence of omitted variables that may be correlated with school quality. A potentially confounding problem is that many studies rely on aggregated (i.e. school district or state-level) school quality data rather 
than school- or classroom-level data. One way to overcome these problems is to follow students who were exposed to dramatically different educational resources for reasons having little to do with their own ability or their parents' wealth. The vastly different treatment of black and white students during the segregation era provides such a setting. One of the most dramatic "natural experiments" involving school resources is furnished by North Carolina and South Carolina. Early in the 20th century, the level of resources devoted to black students was much lower in South Carolina than in North Carolina. Because resources were diverted from black schools to white schools, the reverse was true for whites: school resources were greater for white students in South Carolina than in North Carolina. By mid-century, school resources had converged to roughly similar levels for blacks and whites in the Carolinas. The wide disparities in school quality for black and white students in North and South Carolina in the early part of the century were caused by different, and arguably exogenous, factors than those that generate variability in school resources in most data sets today. Did these

differences in school resources lead to corresponding differences in educational attainment and earnings? Did the economic outcomes for succeeding cohorts converge as school resources converged? Based on our analysis of 1960, 1970, and 1980 Census microdata, the answers to these two questions seem to be yes and yes.

\section{Theoretical Framework}

A useful framework for interpreting much of the literature on schooling, earnings, and school quality can be summarized by four theoretical 
propositions. ${ }^{3}$

Proposition 1: Earnings rise with educational attainment. If two individuals are otherwise identical, the one with more education tends to earn more. This proposition is based on one of the most firmly-established empirical regularities in economics. A positive association between earnings and education holds across individuals even if one controls for other factors, such as IQ, family background, and work experience (Griliches, 1977). It also holds across identical twins with different levels of education, and between groups who obtained different levels of schooling because of compulsory schooling laws or because they grew up near a college (Ashenfelter and Krueger, 1995; Angrist and Krueger, 1991; Harmon and Walker, 1996; Kane and Rouse, 1995; Card, 1995). Although some of the observed correlation between earnings and education may be due to omitted variables -- for example, those with more education may end up with higher earnings because of unobserved ability or family background factors -- our reading of the literature is that this component is relatively small, on the order of 10-15 percent of the total effect. Further, random measurement errors in self-reported schooling may bias downward the observed slope between earnings and education by a similar magnitude.

Proposition 2: The marginal payoff to additional schooling is higher for those who attend higher quality schools. This proposition is almost tautological: one would expect students who have access to higher quality schools to benefit more per year of schooling than students who have access to lower quality schools. ${ }^{4}$ Figure 1, which shows the earnings-education profile rotating counterclockwise from the Y-intercept for those who attend higher quality schools, illustrates the notion that higher quality schooling 


\section{Figure 1: Hypothetical Relationship}

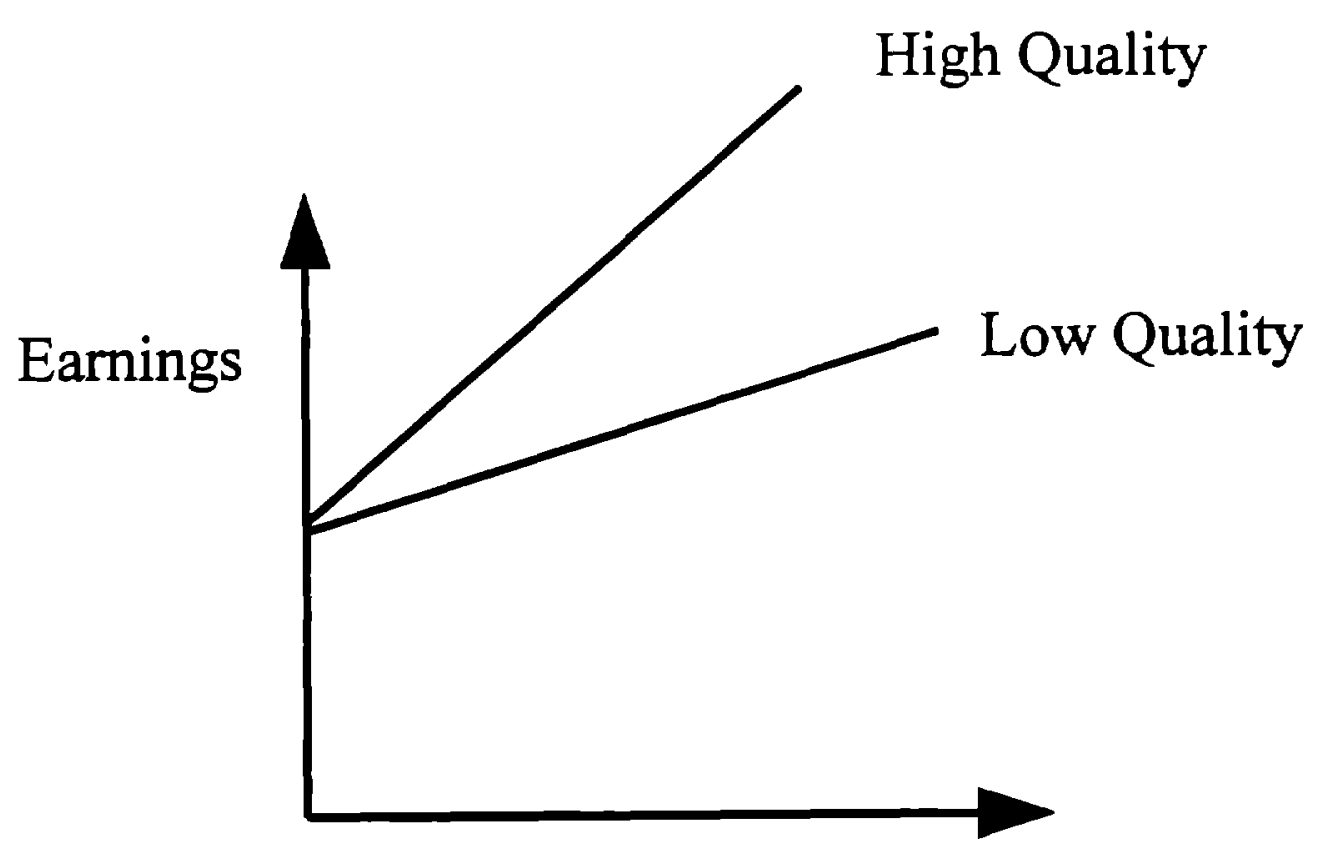

Education 
increases the slope of the earnings-schooling relationship. Note, however, that it is an open question whether measured school resources (such as the pupil-teacher ratio) are related to the more abstract concept of "school quality. "

Proposition 3: If the monetary payoff to an additional year of schooling rises, some students will attend school longer. The observed relationship between school quality and earnings that emerges from a complete model of schooling and earnings is more complicated than that depicted in Figure 1 for several reasons. Importantly, as school quality increases, some students will attend school longer. This response may arise because students react to the economic incentives created by a higher payoff to schooling, or because school is more pleasant if quality is higher. In either event, a wide class of economic models predicts that improved school quality benefits some students by inducing them to stay in school longer, and this increase in educational attainment leads to higher pay.

\section{Proposition 4: A portion of the observed association between earnings} and education is due to unobserved factors that are jointly correlated with both variables. In other words, those who select higher education tend to have greater earnings ability, irrespective of their education. Moreover, students who attend school longer in response to improved school quality (the implication from Proposition 3) will tend to be drawn disproportionately from the pool of more able students at lower grade levels. An interesting implication of this proposition is that the observed earnings-education profile will not rotate around the Y-intercept at a zero level of education as in Figure 1, but at a higher level of education, as illustrated in Figure 2. To understand why, consider what happens to the group of workers with the 
lowest level of education. If school quality improves, the more able workers of this group will attend school longer, lowering the average earnings ability of those who remain at a low level of education, and thus lowering the Yintercept in Figure 2. As school quality improves, the shrinking group of students with a low level of education will increasingly consist of less able individuals, who will appear to earn less, on average.

Omitted factors such as family background or student ability complicate the observed relationship between earnings and measured school quality in other ways as well. Suppose, for example, that students from wealthier families tend to stay in school longer, and that these students would tend to earn more later on because of their family connections, regardless of their higher education. In addition, suppose that wealthier families demand smaller class sizes, even though class size has no effect on actual school "quality" (that is, suppose there is no causal effect of school spending on education or earnings). In this case, the data will show a positive association between school spending and both educational attainment and earnings, although both correlations are spurious, and merely reflect the failure to account for the independent effect of family wealth.

Nevertheless, the presence of omitted family background effects will not necessarily bias the correlation between measured school quality and the slope of the earnings-schooling relationship. To understand why, continue to suppose that children from wealthier family backgrounds in a given school or school district tend to have higher education and higher earnings, so that part of the measured payoff to each additional year of schooling reflects omitted-variables bias. Under reasonable conditions the magnitude of this bias will be similar for students from high-quality and low-quality school 


\section{Figure 2: Observed Relationship}

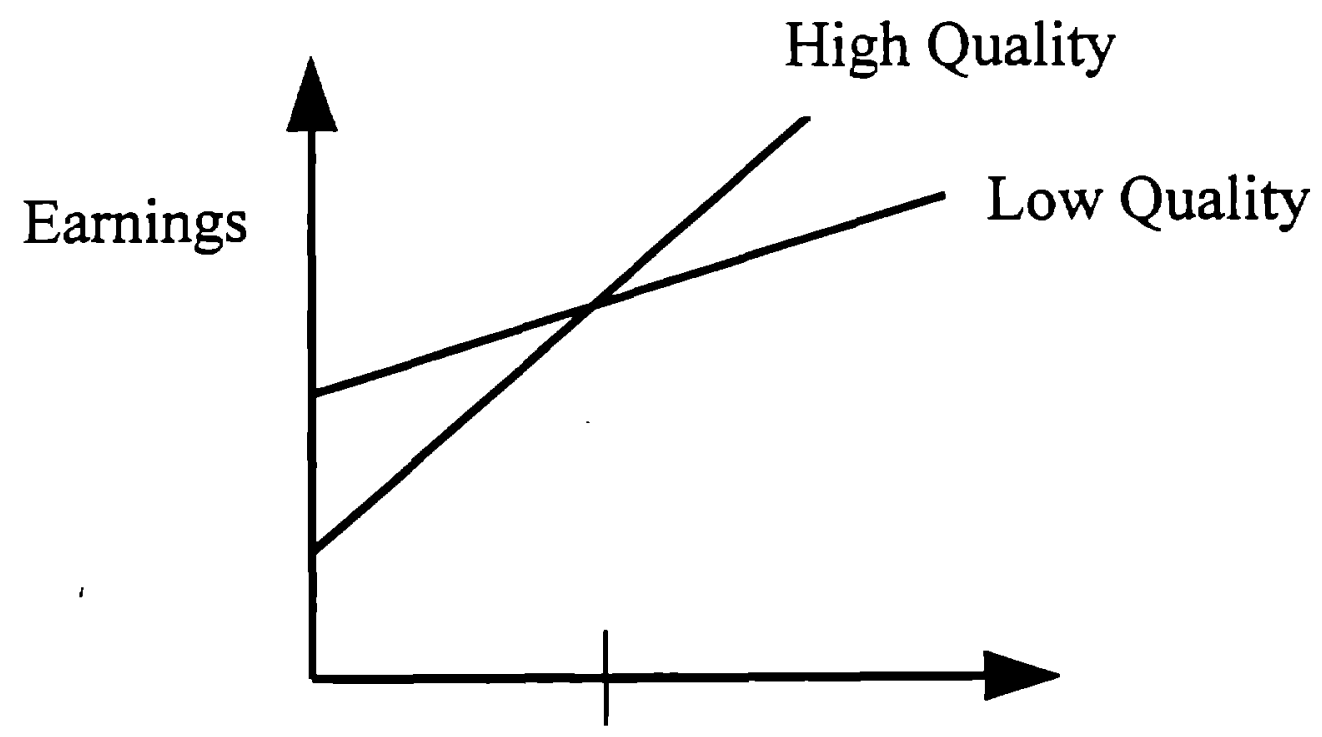

Education 
systems. Thus, comparing across school systems, the measured return to each additional year of schooling would be biased upward by a similar amount. In this case, differences in the slopes of the earnings-schooling relationship across higher and lower quality school systems will reflect true differences in the quality of schooling.

\section{Empirical Findings}

For a detailed survey of the empirical literature on the link between school quality and economic outcomes, the interested reader might begin with Card and Krueger (1996) and Betts (1996). Here, we concentrate on summarizing the effect of two particular educational imputs -- expenditures per pupil and the pupil-teacher ratio -- on educational attainment and earnings. We emphasize the pupil-teacher ratio because differences in class size account for close to one-half of the variation in expenditure per pupil across school districts, and because changes in class size are the object of many educational reform proposals.

The theoretical framework outlined above suggests two empirical strategies. In one approach, the structural earnings-schooling relationship illustrated in Figure 2 can be estimated, along with the effect of school quality, as measured by expenditures per pupil or the pupil-teacher ratio, on educational attainment. Alternatively, one can estimate the reduced form relationship between earnings and school resources; that is, a regression of earnings on measures of school quality like expenditures per pupil or the pupil-teacher ratio, without holding educational attainment constant.

The earliest wave of studies on school resources and economic outcomes, 
conducted in the late 1960s and 1970s, followed a third approach: researchers simply added measures of school quality to a standard human capital wage equation. Such models typically used educational attainment, work experience, parental education, urban residence, and in some cases, IQ as explanatory variables. Earnings were based on individual observations. When a variable representing school quality was added, it was usually measured by average expenditures per pupil at the state or district level. All of these studies found that spending per student was positively associated with students' subsequent earnings, and most of the estimates were statistically significant at conventional levels. ${ }^{5}$ The estimated elasticities from this literature fall in a fairly tight range: a 10 percent increase in school spending leads to about a 1 to 2 percent increase in subsequent earnings.

These specifications imply that the earnings-education profile has a fixed slope, and that differences in school quality make this relationship shift up and down in a parallel fashion, as opposed to a tilting of the profile shown in Figure 1. A potentially undesirable feature of this specification is that it implies that more school resources raise (or lower) earnings by the same amount, regardless of the length of time that students are exposed to the greater resources in school. Additionally, because the studies hold educational attainment constant, the possibility that improved school quality might lead to higher wages by encouraging students to attend school longer is missed.

A second wave of studies allowed for school resources to have a differential effect on the slope and intercept of the earnings-education relationship. For example, Akin and Garfinkle (1980) estimate several wage regressions using micro data from the Panel Study on Income Dynamics (PSID). 
The dependent variable in their specification is the log of the wage rate (averaged over 5 years), and the key explanatory variables of interest are state expenditures per student (in the decade in which the workers would have attended school), expenditures per student times years of education, and years of education. Their results indicate that greater spending per student is associated with higher earnings, but contrary to the prediction in Figure 2, the effect comes about from an upward shift in the Y-intercept rather than a steepening of the education gradient. Link, Ratledge and Lewis (1980) replicate Akin and Garfinkle model with the PSID as well as with the National Longitudinal Survey (NLS) of Young Men, and generally find similar results. ${ }^{6}$ Interestingly, both studies also find that if school resources are constrained to only affect the earnings-education slope, the earnings profile rotates as in Figure 1. In a recent paper, Altonji and Dunn (1996) use within-family differences in school resources to estimate this type of model with data from the NLS. By looking within families, they adjust for differences in omitted family background factors. Their findings imply that a 10 percent increase in spending per student is associated with a 1.3 percent increase in earnings. Interestingly, they find the estimated effect of school resources is greater, not smaller, when family background characteristics are held constant.

A potential problem with these second-wave studies is that the reward to skills may vary systematically across geographic areas with varying levels of school resources, and workers tend to stay in the area where they grew up. For example, in the southern United States the return to education historically has been relatively high, while wages and school spending per student were relatively low. This pattern could make it appear that higher school spending depresses the return to education, when the truth is that the 
south has invested less in education, keeping its return relatively high, and north-south migration has been insufficient to reduce the differential. Thus, the second-wave estimates may confound labor market effects and school resource effects.

A third wave of estimates attempts to overcome problems caused by differential labor market structures across regions. ${ }^{7}$ The conceptual experiment underlying these estimates is straightforward. Consider the workers observed in a particular labor market, say Chicago. Some workers in Chicago were educated in states with higher quality school systems and others were educated in states with lower quality schools. Among those working in Chicago, we would expect the earnings-education gradient to be steeper for workers who were educated in states with higher quality schools. A weakness of this strategy is that there may be something "unusual" about those who moved from one area to another that confounds the effect of school resources.

In Card and Krueger (1992a) we find that, in a given set of labor markets, the earnings-education slope does tend to increase for students who were educated in states with fewer pupils per teacher, higher average teacher pay, or a longer school year. In other words, the payoff to each additional year of education is greater for workers who come from areas with more resource-intensive schools, looking within a fixed labor market. This finding is strongest when cohorts from given states are cormpared over time, which removes any effect of permanent state effects (such as unchanging state-level political variables). Identification of school-resource effects in these fixed-effects models comes from conparing successive cohorts of individuals from states like Alabama, which raised their school spending relative to other states like New York. Further analysis indicates that the earnings-intercept 
tends to decline as resources increase. In short, the earnings relationship appears to pivot around a mid-level of education, as illustrated in Figure 2 . We found that the cross-over point in Figure 2 occurs around the high school graduate level. our analysis makes use of the large samples afforded by the 1980 Census.

Heckman, Layne-Farrar and Todd (1996) extend this analysis using the 1970, 1980 and 1990 Censuses. When they estimate virtually the same models as ours, they find similar effects of school resources in 1980, and somewhat larger effects in 1970 and 1990. The finding of larger effects of school resources in 1970 and 1990 is perhaps not surprising, since the payoff to education in general was at a relatively low level in 1980. Heckman, LayneFarrar and Todd also find that the intercept of the earnings-education relationship declines as school resources increase.

Heckman, Layne-Farrar and Todd (1996) expand our basic econometric specification in several important directions. When they include regional aggregate supply and demand variables, the general pattern of results holds up. But when they allow for differential school resource effects by level of education, they find that school resources have little effect on earnings for workers who have not attended school beyond high school. The only education group for which resources are significantly related to earnings are those with a college education or higher. As school resources are measured at the secondary or elementary school level, this result may seem perplexing. One interpretation, however, is that higher school quality induces the most promising students to go further in school at each grade level, so the sarmple at each level of education becomes more select as school resources change. ${ }^{8}$ Nonetheless, the effects of selective educational attainment are just 
conjecture at this stage, and the interpretation of the earnings-quality relationship conditional on education is still an open question. The reduced form models, which do not condition on education, provide one way of sidestepping this issue.

Another assumption that Heckman, Layne-Farrar and Todd (1996) relax is the restriction that school quality has the same effect on the earningseducation slope in all regions. Regional differences in supply and demand conditions may alter the payoff to skills, and hence school quality, across regions. A related issue that they address is non-random migration. Workers may selectively sort across regions based on their comparative earnings advantage. (As noted earlier, the identification of school resource effects in Card and Krueger (1992a) relies on the fact that migrants from states with different levels of school quality end up working in a common labor market.) As a partial control for selective migration, Heckman, Layne-Farrar and Todd control for the distance between the workers' region of origin and destination. These extensions weaken the effect of school resources, and suggest that the return to higher school quality, as measured by the pupilteacher ratio, varies across regions. 9

The finding that school quality raises wages is not found in every data set. For example, using data from the National Longitudinal survey of Youth (NLSY), Betts (1995) finds a statistically insignificant effect of school resources (measured by the high school's teacher-pupil ratio, teacher salary, and so on) on the earnings of young workers -- on either the slope or the intercept in Figure 2. These data have important limitations for this purpose, however. The standard errors of the estimates from the NLSY are large, making it difficult to rule out small positive effects with a 
reasonable degree of confidence. ${ }^{10}$ In addition, the sample has an average age of just 23, which means that many of the individuals have not yet finished school or settled into their careers, so wage effects for those with higher levels of schooling may be difficult to find. Nonetheless, Betts and others have interpreted his findings as evidence that school resources do not matter when the resources are measured at the school level, as opposed to the state or district level. We return to this point below.

Recall that school resources may also influence educational attainment. A majority of the studies of which we are aware have found positive and statistically significant effects of smaller class size on educational attainment. Some of these studies use micro data on individual's educational outcomes and school resources, while others use state- or district-level data. For example, Sander (1993) relates high school graduation rates to the pupilteacher ratio across 154 Illinois school districts, and for a subsample of 86 school districts in which there is only one high school in the district. In both cases he finds that a 10 percent decrease in the pupil-teacher ratio is associated with about a 1.5 percentage point increase in the graduation rate. Heckman, Layne-Farrar and Todd (1996) likewise find that a reduction in a state's pupil-teacher ratio tends to reduce the fraction of high school dropouts from that state, and to raise fraction of individuals who graduate from high school and (especially) college.

An advantage of the reduced form estimation approach -- which involves a regression of earnings on school quality measures without controlling for educational attainment -- is that it incorporates all the possible effects of school resources: on educational attainment, on the earnings-education profile, and on the intercept of the eamings-schooling relationship. In Card 
and Krueger (1992a), we estimate a reduced form regression of (log) weekly wages on the state's pupil-teacher ratio, the worker's age and marital status, and dummy variables for residence in a metropolitan area, the state where the worker lives, and (in some models) the state where the worker was born. These models are relatively parsimonious, and so are particularly susceptible to confounding effects from onitted variables. Nevertheless, the reduced from models have the advantage of making less restrictive identifying assumptions, and are probably the most comparable specifications estimated across papers in the recent literature. our 1992a reduced form estimates based on the 1980 Census imply that a 10 percent reduction in the average pupil-teacher ratio is associated with a 1.1 percent increase in weekly earnings. Betts's (1995) estimates, which are based on NLSY earnings data and high school-level schooling data, imply that a 10 percent reduction in the average teacher-pupil ratio leads to a 0.4 percent increase in earnings. ${ }^{11}$ Using the High School and Beyond survey, Grogger's (1996) reduced form estimates imply that a 10 percent increase in mean spending per student leads to a 0.7 percent increase in wages.

To summarize, much of the literature finds evidence of a positive and statistically significant relationship between school resources and earnings. By our count, some two-thirds of the two dozen studies on the impact of school spending or class size on earnings have found a statically significant, positive effect of school resources (Card and Krueger, 1996). Positive effects of class size on educational attainment are also typically found in the literature.

But we do not wish to paint an overly optimistic picture. Several important studies find statistically insignificant effects of changing school 
resources. Heckman, Layne-Farrar and Todd (1996) have shown that the effect of school resources measured in Card and Krueger (1992a) break down when some of the identifying assumptions (e.g., linear education) are relaxed.

Moreover, there are always questions in observational studies as to whether relevant variables have been left out. Because wealthier families tend to invest more in their children at home, and to live in communities with better endowed schools, omitted family background may be a particular problem.

Betts (1996) and Hanushek (1996) note that biases created by omitted variables are possibly larger in studies that measure school resources at a more aggregative level, like the state or school district level. Hanushek, Rivkin and Taylor (1996) argue that state political variables are a particular problem for aggregate studies. Although this is possible, the fact that the models reported in Card and Krueger (1992a) and Heckman, Layne-Farrar and Todd (1996) that include state-fixed effects tend to show larger, rather than smaller, effects of school quality suggests to us that onitted state-level variables may lead to the opposite bias. In any event, the argument that omitted variables are a bigger problem for studies that use aggregate school quality data would be stronger if such omitted variables could be identified, and if their inclusion in the regression models was shown to attenuate the effect of aggregate school resource measures.

A related problem concerns the endogeneity of school resources within schools (or within school districts). Children who perform poorly may be assigned to smaller classes, for example. With individual-level resource data, this may lead to downward-biased estimates of the effects of school resources. On the other hand, highly motivated children may be attracted to magnet schools with higher resources per pupil, leading to upward-biased 
estimates. In either case, the use of aggregated school quality measures will tend to lessen the biases of endogenous school resources within schools or districts. Finally, measurement error in school resources should be a cause for concern. Even the best micro data sets tend to have school resource data for one year, providing only a snapshot of the student's educational career, while district- or state-level resource data are more likely to "average out" year-to-year fluctuations in resources. Aggregated data reduce or eliminate random measurement errors that make it difficult to detect school resource effects using micro-level school quality data.

Ideally, these sources of bias could be eliminated by a randomized experiment, in which students are assigned to classes with different pupilteacher ratios (or differences in other resources) and then followed over time. We are aware of only one large-scale randomized experiment involving class sizes, which pertained to elementary students in Tennessee (Mosteller, 1995). This experiment showed a positive effect of lower class size on test scores at the lowest grades. We know of no randomized experiment that has been used to evaluate economic outcomes of schooling. In the absence of a true random experiment, it may be useful to consider the evidence generated by "natural experiments" -- situations in which large differences in school resources were provided to seemingly similar individuals for arbitrary reasons. One interesting example of such a situation is the experience of black and white students in North and South Carolina, to which we now tum.

\section{A Comparison of North and South Carolina}

Racially segregated schooling led to profound differences in the level 
of school resources available to black and white children in different areas of the United States in the first half of this century. A striking comparison is provided by two neighboring states: North Carolina and South Carolina. Figure 3 displays the pupil-teacher ratio in black and white schools in the two states over the past century. ${ }^{12}$ Although the Carolinas are similar in some respects, they differed dramatically in terms of the school resources they provided for black and white children. Whereas North Carolina was among the most progressive of the non-border Southern states vis-a-vis black schooling, South Carolina was among the least progressive (Harlan, 1958). For white students, the pattern was reversed: schools were better funded in South Carolina than in North Carolina throughout the first half of the century. In 1916, for example, black schools had 72 students per teacher in South Carolina and 47 in North Carolina, while white schools had 41 students per teacher in North Carolina and 37 in South Carolina. The school term was also much shorter for blacks in South Carolina than in North Carolina, while the opposite pattern held for whites. In both states, the pupil-teacher ratios in black and white schools converged to almost the same level by the late 1960s. ${ }^{13}$

What caused the great disparities in school resources for black and white students in North and South Carolina? Researchers from Bond (1934) to Margo (1990) have observed that in areas where blacks were more numerous, a greater share of school resources were diverted from the black schools to white schools, raising the resources in white schools and depressing them in black schools. An exclusionary political system enabled this discriminatory practice to persist until the 1960s (Boozer, Krueger and Wolkon, 1992). Viewed in this light, the Carolina's varying experiences largely came about by 


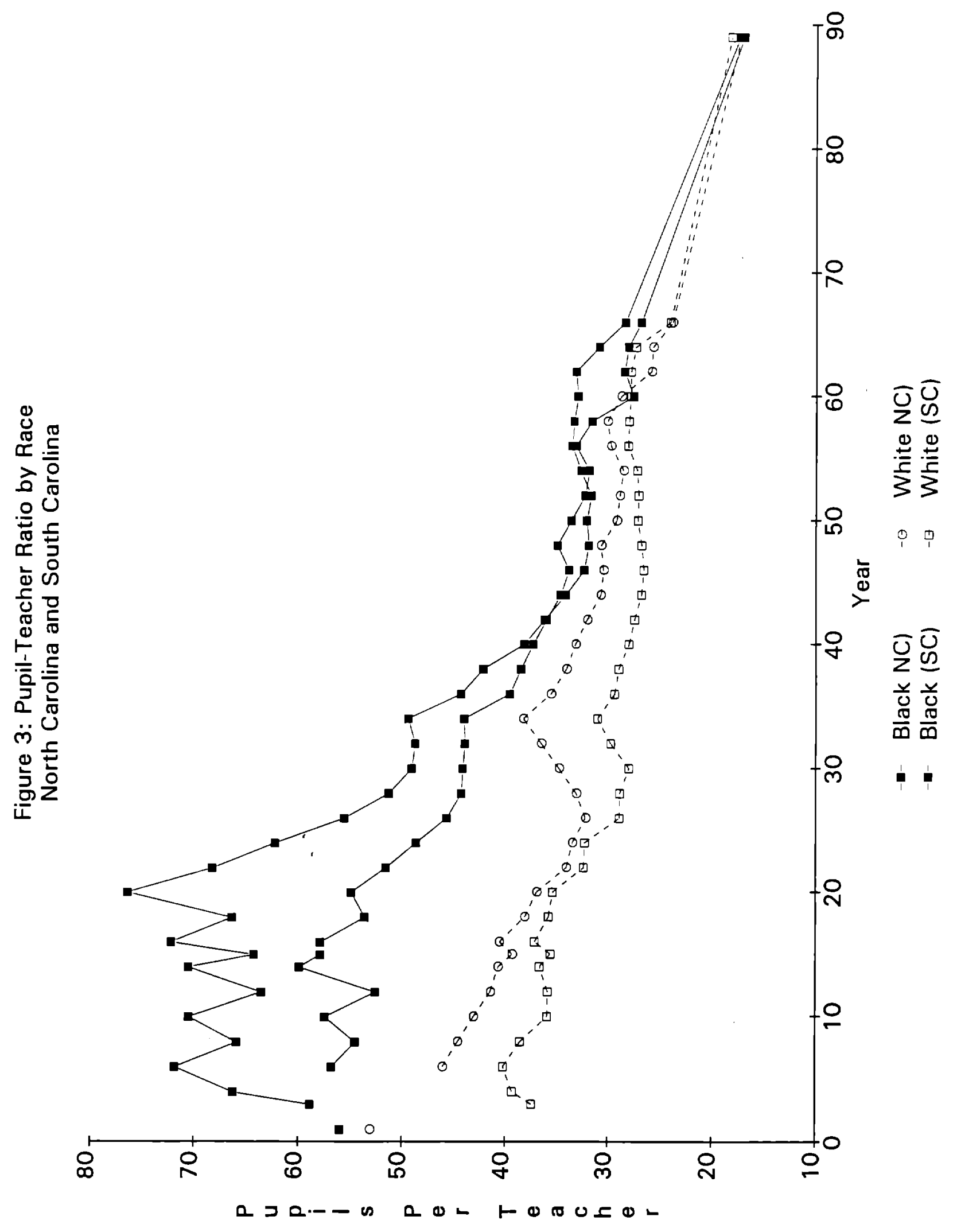


historical accident. South Carolina had a much higher proportion of blacks in its population than North Carolina (58 percent of South Carolinians were black in 1900 versus 33 percent of North Carolinians), in part because of historical differences in slave populations driven by different cropping patterns (Fogel and Engerman, 1974). In South Carolina, cotton was the most important crop, whereas in North Carolina, tobacco was more important.

The experiences of North and South Carolina provide a potentially useful laboratory for evaluating the effect of school resources. A very different set of forces led to differences in school resources for students in these two states than the factors that determine resource decisions in a typical school district today. If omitted variables plague aggregate studies of earnings, we would not expect to find earnings and educational attainment mirroring racial differences in school resources in South and North Carolina over time, unless these omitted state variables somehow changed along with the allocation of school resources. It is therefore valuable to check whether the convergence in school resources for whites and blacks from North and South Carolina led to a parallel convergence in the relative levels of educational attainment and earnings for individuals from the two states.

We used microdata from the 1960, 1970 and 1980 Censuses to examine trends in education and earnings for succeeding generations of men born in the Carolinas between 1900 and 1959. We restrict the sample to men because labor force participation rates were much lower for women. For convenience, we group together men from 10-year birth cohorts. (The details of the sample and statistical analysis are described in more depth in the Appendix.) Figure 4 shows trends in average educational attainment by race for each cohort of North and South Carolinians. The corresponding differences in average 
Figure 4

\section{Average Education Levels by Cohort Men Born in NC and SC}

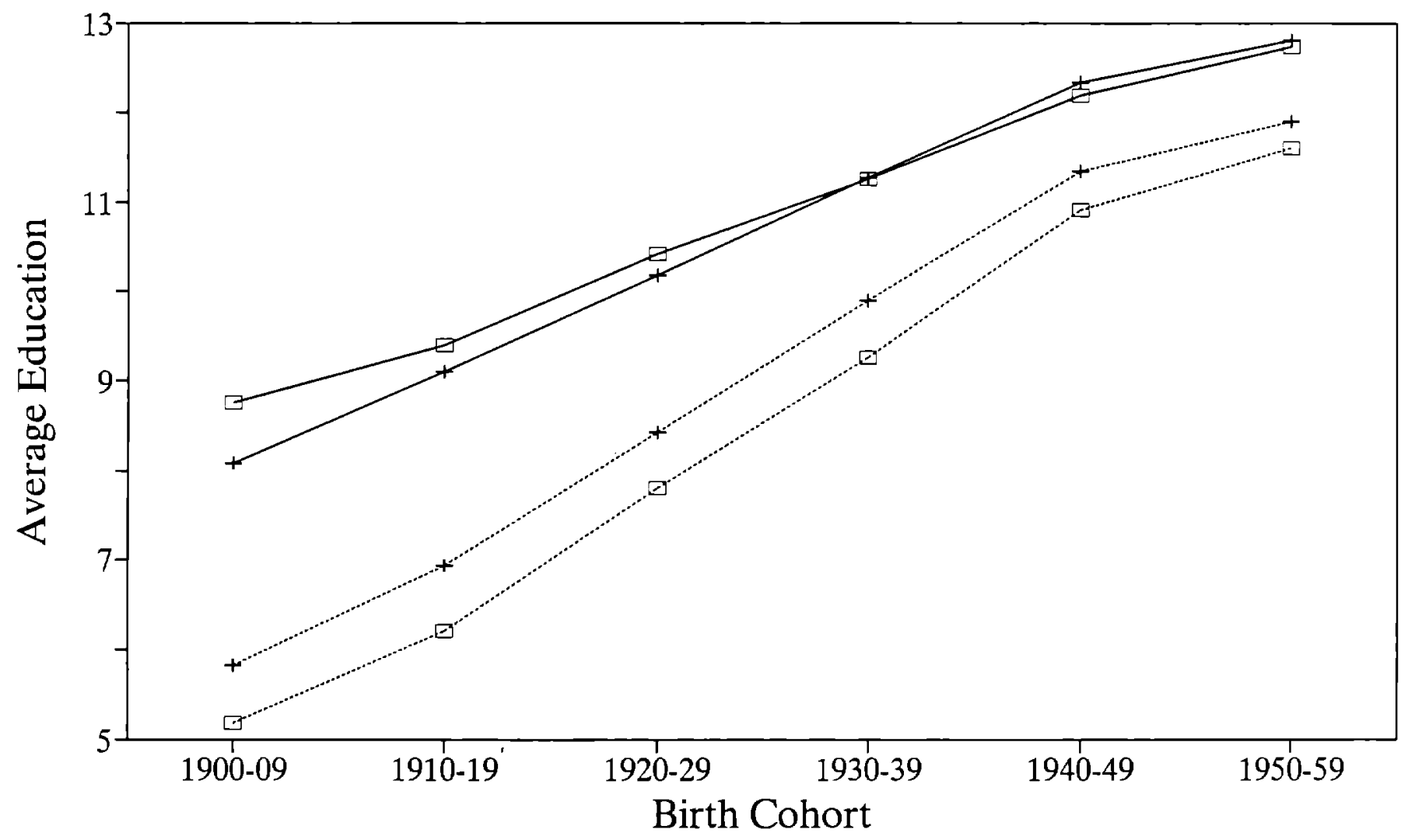

$\sqsupset$ Whites, $\mathrm{SC} \longrightarrow$ Whites, $\mathrm{NC} \cdots+\cdots$ Blacks, NC ㄷ.. Blacks, SC 
education by race and cohort are presented in columns 2 and 5 of Table 1. Examination of the data in the figure and table suggests that trends in relative education between the two states roughly mirror the trends in relative school resources by race. For the 1900-1909 birth cohort, blacks in North Carolina had about 14 fewer pupils per student that blacks in South Carolina. This gap was associated with 0.65 more years of education, on average, for blacks born in North Carolina. For whites in the same cohort, the situation was reversed. Whites in South Carolina had about 4 fewer pupils per teacher, and this gap was associated with a 0.67 year education gap in favor of South Carolina-born whites. For both blacks and whites, the education gaps narrowed over succeeding generations, as the resource gaps closed between the states.

Trends for earnings point in the same direction, but are noisier. Columns 3 and 4 of Table 1 report regression-adjusted mean earnings gaps by race for cohorts of men from North and South Carolina. The main motivation for the regression adjustment is to compensate for differences in earnings associated with working in different regions of the country and in a metropolitan as opposed to non-metropolitan area (see the Appendix for further details). ${ }^{14}$ In essence, the estimated wage differentials are standardized so as to compare individuals who work in the same job market.

Looking at black men in the 1900-09 birth cohort, those from North Carolina enjoyed a 6 percent wage advantage over their counterparts from South Carolina. In contrast, white men in this cohort from South Carolina enjoyed a 7 percent wage advantage over their counterparts from North Carolina. In both cases, the wage gaps vanished over succeeding generations. The pattern of the North Carolina-South Carolina wage differentials by race and cohort are 
Table 1: Differences in Pupil-Teacher Ratio, Education and Earnings Between Men Born in North and South Carolina By Race and Birth Cohort

Mean for North Carolina - Mean for South Carolina:

Blacks

\begin{tabular}{llll}
\cline { 2 - 3 } Birth & & & Log \\
Cohort: & P/T Ratio Education & Earnings
\end{tabular}

(1)

(2)

\begin{tabular}{lcccccc}
\hline & & & & & & \\
$1900-09$ & -13.6 & 0.65 & 0.06 & 3.9 & -0.67 & -0.08 \\
& & $(0.10)$ & $(0.02)$ & & $(0.08)$ & $(0.02)$ \\
$1910-19$ & -9.7 & 0.73 & -0.02 & 4.0 & -0.29 & -0.03 \\
& & $(0.07)$ & $(0.02)$ & & $(0.05)$ & $(0.01)$ \\
$1920-29$ & -4.2 & 0.62 & 0.01 & 6.0 & -0.25 & -0.04 \\
& & $(0.06)$ & $(0.01)$ & & $(0.05)$ & $(0.01)$ \\
$1930-39$ & 0.5 & 0.64 & 0.01 & 3.9 & 0.03 & -0.02 \\
& & $(0.07)$ & $(0.02)$ & & $(0.05)$ & $(0.01)$ \\
$1940-49$ & -1.7 & 0.43 & 0.01 & 1.1 & 0.14 & -0.03 \\
& & $(0.08)$ & $(0.02)$ & & $(0.06)$ & $(0.01)$ \\
1950-59 & -1.1 & 0.30 & 0.02 & -0.5 & 0.07 & -0.02 \\
& & $(0.12)$ & $(0.03)$ & & $(0.09)$ & $(0.02)$ \\
Difference & & & & & & \\
Between Cohorts: & & & & & & \\
$1940-49-$ & 11.9 & -0.22 & -0.05 & -2.8 & 0.81 & 0.05 \\
$1900-09:$ & & $(0.13)$ & $(0.03)$ & & $(0.10)$ & $(0.02)$ \\
$1950-59-$ & 12.5 & -0.35 & -0.04 & -4.4 & 0.74 & 0.05 \\
$1900-09:$ & & $(0.16)$ & $(0.04)$ & & $(0.12)$ & $(0.02)$ \\
\hline
\end{tabular}

Whites

$\begin{array}{ll} & \text { Log } \\ \text { P/T Ratio Education } & \text { Eamings }\end{array}$

(4)

(5)
(6)

Notes: Standard errors in parentheses.

Based on authors' tabulations of state school system data and tabulations of 1960, 1970, and 1980 Census data. See Appendix for data sources.

Reported coefficients are the mean for North Carolina minus the mean for South Carolina. P/T Ratio refers to the average pupil-teacher ratio in the state for a representative member of each race/birth cohort, assuming 10 years of education. Education refers to mean years of cormleted education for all men in the respective race/birth cohort group. Earnings refer to mean log eamings for those with positive earnings, adjusting for state/region of residence, residence in an SMSA, year of observation, and age at Census. See Appendix for details. 
consistent with the view that meager school resources put black men from South Carolina at competitive disadvantage, while generous resources gave white men from South Carolina a leg up in the job market. One troubling finding for this interpretation, however, is that the cross-state wage gaps seemed to close very quickly for blacks, whereas the school quality gap was more persistent. Given the sampling variability of the estimates, however, the cohort-specific wage gaps should be viewed cautiously.

How consistent are the data in Table 1 with the earlier literature on earnings and school quality? To answer this question, recall that the reduced form estimates in the literature suggest that a 10 percent reduction in class size would be associated with an increase in earnings of 0.4 to 1.1 percent. Thus, the roughly 12 student narrowing of the gap in the average pupil-teacher ratio between North and South Carolina for blacks born in the 1940s relative to those born in the 1900s (a 28 percent reduction) might have been expected to raise earnings by $1-3$ percent. ${ }^{15}$ The actual narrowing in the earnings gap was about 5 percent (with a standard error of 3 percent) -- roughly consistent with the earlier literature. The patterns for whites are somewhat harder to explain, since the relative change in school quality is modest. Based on earlier estimates, the 3 student reduction in the pupil-teacher ratio gap between North and South Carolina whites born in the 1940s relative to those born in the 1900s might have been expected to raise earnings by $0.4-1.1$ percent, while the actual earnings convergence was also 5 percent (with a standard error of 2 percent). One possible explanation for the larger than expected wage differences is that other aspects of school resources, such as the length of the school year, differed substantially between North and South Carolina early in the century as well, and then converged. 
We conclude that the magnitude of the observed earnings convergence for black men in the two states is roughly consistent with the earlier literature, while the magnitude of convergence for white men is, if anything, greater than expected. However, despite the strong intuitive appeal of the North Carolina - South Carolina comparison on a priori grounds, and the availability of over 130,000 wage observations from the 1960, 1970, and 1980 Censuses, it is evident that the power of the data to yield precise estimates of cross-state earnings differentials by race and cohort is limited. There is a general lesson here. Because eamings are so variable, and school resource effects are at best modest, small data sets are unlikely to find significant effects of school resources.

South Carolina and North Carolina represent just one possible comparison. What about the other segregated states? In Card and Krueger (1992b), we use data from all 18 segregated states to relate the level of school resources in the black and white schools to subsequent earnings of individuals educated in those states. To control for differential labor market effects, in much of our analysis we focused on workers who attended school in the South but later were observed working in a cormon set of Northern labor markets. This technique has the advantage of controlling for labor market differences that may be correlated with school quality differences: for example, states that discriminated in terms of school resources may be more likely to allow discrimination in terms of labor market conditions. The results indicated that the payoff to each year of education was greater for individuals (of either racial group) who were from states that devoted more resources to education. Furthermore, reduced form models indicate that the level of earnings and educational attainment were positively 
associated with school resources. Thus, the comparison of North and South Carolina is not an isolated example.

\section{Conclusion}

Does the literature on school resources, earnings, and educational attainment prove beyond a reasonable doubt that resources matter? We do not believe that the evidence justifies so strong a conclusion. The available evidence is not unambiguous or ubiquitous, and suffers from all the standard criticisms of drawing causal inferences from observational data.

To some extent, interpreting the literature depends on the strength of one's prior expectations. If one starts from the position that school resources do not make a difference, then one can point to the bulk of the evidence on the lack of a statistically significant connection between school resources and test scores, and a handful of studies on economic outcomes, to support that view. On the other hand, if one starts from the view that resources do make a difference, then the available evidence on school quality and economic outcomes may be interpreted as generally supportive. Perhaps the strongest evidence that resources matter comes from an analysis of the vast differences in resources for blacks and whites who attended schools in the segregated states. We suspect that further research focussing on particular episodes of large changes in school quality -- such as our simple "case study" of North and South Carolina -- might be valuable.

Thirty years after the coleman Report, it is unfortunate and frustrating that more is not known about schooling. While most of the literature on test scores points to little, if any, effect of school resources, some 
observational studies and one actual experiment, have found a connection. Decisions about educational resources and reform have to be made in an environment of much uncertainty. 


\section{Appendix}

Description of Data used in the North and South Carolina Comparison

The estimates in Figure 4 and Table 1 are based on samples drawn from the Public Use Sarmples of the U.S. Census. Specifically, the sample is drawn from the 1960 1\% public use sample, the 1970 1\% sample (15\% form) and the 1970 1\% sarmple ( $5 \%$ form), and the 5\% sample of the 1980 Census. In principle, the Census provides self-weighting samples of the population. Thus, the sample contains $1 \%$ of the population in 1960, 2\% in 1970 and 5\% in 1980. We assigned sample weights so that the sample each Census year received equal weight (that is, observations from 1960 were assigned a weight of 1.0, observations from 1970 were assigned a weight of 0.5 , and observations from 1980 were assigned a weight of 0.2 ). Our extract consists of white and black men born in North Carolina or South Carolina between 1900 and 1959, who were age 25 to 65 at the time the Census was conducted. These restrictions yielded a sample of 168,353 observations. Education is measured as the highest year of schooling completed. Figure 3 simply reports average education level by 10-year-ofbirth cohort, race, and state of birth.

Further restrictions were placed on the sample for the analysis of annual earnings in Table 1. First, wage and salary income was converted to 1995 dollars using the CPI-U. The sample was then restricted to men with annual wage and salary income of at least $\$ 500$, and weekly wage and salary income between $\$ 30$ and $\$ 2,500$. Restricting the sample to those with non-zero wage and salary earnings reduced the sample by $19 \%$, and restricting the range of the annual and weekly wage recuced the sample by an additional $2 \%$. The 
final sample used for the analysis of earnings thus has 132,989 observations $(40,837$ blacks and 92,152 whites $)$.

The estimates reported in Table 1 were derived from regressions of log annual earnings on ten-year birth cohort dumies and their interactions with a born-in-North Carolina dummy, a 1970 year dunmy, a 1980 year dummy, 9 region of residence dumies interacted with three Census year dummies, dumies indicating residence in North Carolina and South Carolina, a dummy variable indicating whether the worker lives in a standard metropolitan statistical area (SMSA) interacted with Census year, and a cubic in current age. Separate weighted regressions were estimated for blacks and whites. The coefficient on the cohort dummies interacted with the born-in-North Carolina dummy are reported in Table 1 . Subject to the log approximation, these coefficients can be interpreted as the proportionate difference in earnings between workers from North and South Carolina who live in the same region, for each cohort and race. 


\section{Endnotes}

1. See Glass and Smith, 1978; McGiverin, Gilman and Tillitski, 1989 ; Hedges and Stock, 1983.

2. If all the estimates with unknown signs are counted as negative, the odds are still less than one in 100 . On the other hand, Hanushek finds a much weaker pattern for the teacher-pupil ratio. But one must wonder whether some of these studies controlled for both the teacher-pupil ratio and expenditures per student in their estimating equations.

3. This model is developed formally in Card and Krueger (1996). Also see Lang (1993) for a related model.

4. This analysis ignores any general equilibrium effects of changing the endowment of human capital. This assumption can be justified if the school system under consideration is small relative to the rest of the economy, so the price of human capital is set exogenously in the market.

5. Examples of this literature include Morgan and Sirageldin (1968), Johnson and Stafford (1973), and Rizzuto and wachtel (1980). An example that found an insignificant positive effect of school resources is Ribich and Murphy (1975).

6. School spending per student in the NLS data pertains to the average secondary school in the district where the worker lived.

7. A seminal paper of this genre is by Behrman and Birdsall (1983), which studies school resources in Brazil. Because the emphasis in this paper is on the United States, however, we do not describe their findings in detail.

8. By analogy, a high quality undergraduate economics program is likely to have its most beneficial effect on students who continue on to graduate school. Would any department chair want his or her program evaluated on the basis of a sample that explicitly excludes students who continue on to graduate school?

9. Although Heckman, Layne-Farrar and Todd (1996) find that school resources have a varying effect on the earnings-education slope across regions, in most regions, a smaller pupil-teacher ratio is associated with a higher payoff to additional education.

10. Betts (1995) does not adjust the standard errors of his estimates for the fact that there are as many as 10 wage observations per individual in the NLSY sample. Betts generously provided us with his data, and we have used his sample to calculate standard errors that account for the correlation across earnings 
observations for the same individual over time. This adjustment raises the estimated standard errors by up to 100 percent.

11. These elasticities are calculated at the means of their respective data sets. The t-ratio of the Card and Krueger estimate reported in this paragraph is 6.2 ; for the Betts estimate, it is 1.7. However, both t-ratios are probably overstated because of multiple earnings observations per worker or per state. In specifications that include cumulative work experience rather than age, Betts finds a weaker effect of the teacher-pupil ratio. Because work experience may be influenced by educational attainment, which in turn may be influenced by school resources, we chose to hold constant age instead of experience in the reduced form models in our 1992a article.

12. The data used to construct this figure are taken primarily from the U.S. Office of Education's Biennial Survey of Education and from various state education reports.

13. Despite the 1954 Brown $v$. Board of Education decision, substantial school integration did not begin until the mid-1960s.

14. Interestingly, the data show that South Carolina blacks in the earliest birth cohorts were more likely to move to higher wage urban areas outside the South than North Carolina blacks. Without any adjustment for region of residence, average wages of South Carolina blacks in the earlier cohorts are therefore quite similar to averages for North Carolina blacks.

15. The 12 student reduction in relative class size is roughly a 28 percent reduction; that is, average class size in North Carolina for the 1900-09 cohort of blacks was 55.7 and for the 1940-49 cohort was 31) 
References

Akin, John S. and Irwin Garfinkel. (1980). "The Quality of Education and Cohort Variation in Black-White Earnings Differentials: Comment." American Economic Review 70 (March): 186-191.

Altonji, Joseph and Thomas Dunn. 1996. "Using Siblings to Estimate the Effect of School quality on Wages." Forthcoming, Review of Economics and Statistics.

Angrist, Joshua D. and Alan B. Krueger. (1991). "Does Compulsory Schooling Affect Schooling and Earnings?" Quarterly Journal of Economics 106 (November) : 979-1014.

Behrman, Jere and Nancy Birdsall. (1983). "The Quality of Schooling: Quantity Alone is Misleading." American Economic Review 73 (December) :928946.

Betts, Julian. (1995). "Does School Quality Matter? Evidence from the National Longitudinal Survey of Youth." Review of Economics and Statistics 77, no. $2: 231-250$.

Betts, Julian. (forthcoming 1996). "Is There a Link Between School Inputs and Earnings? Fresh Scrutiny of an Old Literature." In Gary Burtless, editor, The Link Between Schools, Student Achievement, and Adult Success. Washington D.C.: Brookings Institution.

Bond, Horace Mann. (1934). The Education of the Negro in the American Social Order. New York: Prentice Hall.

Boozer, Michael, Alan Krueger, and Shari Wolkon. (1992). "Race and School Quality Since Brown vs. Board of Education." Brookings Papers on 
Economic Activity: Microeconomics, Martin N. Baily and Clifford Winston (eds.) : pp. 269-326.

Card, David. (1995). "Schooling, Earnings and Ability Revisited." In Solomon Polachek, editor, Research in Labor Economics (volume 14). Greenwich Connecticut: JAI Press.

Card, David and Alan B. Krueger. (1992a). "Does School quality Matter? Returns to Education and the Characteristics of Public Schools in the United States." Journal of Political Econony 100 (February): 1-40.

Card, David and Alan B. Krueger. (1992b) . "School quality and BlackWhite Relative Earnings: A Direct Assessment." Quarterly Journal of Economics 107 (February): 151-200.

Card, David and Alan B. Krueger. (1996). "Labor Market Effects of School Quality: Theory and Evidence." In Gary Burtless, editor, Does Money Matter? The Effect of School Resources on Student Achievement and Adult Success Washington D.C.: Brookings Institution, 1996, pp. 97-140.

Coleman, James S., and others. 1966. Equality of Educational Opportunity (Department of Health, Education and Welfare).

Fogel, Robert and Stanley Engerman. (1974). Time on the Cross. Boston: Little Brown.

Glass, Gene, and M.L. Smith. 1978. Meta-analysis of Research on the Relationships of Class Size and Achievement. ERIC Document Reproduction Service No. ED 168129.

Griliches, Zvi. (1977). "Estimating the Returns to Schooling: Some Econometric Problems." Econometrica 45 (January) : 1-22.

Jeff Grogger. 1996. "School Expenditures and Post-Schooling Earnings: Evidence from High School and Beyond." Forthcoming, Review of Economics and 


\section{Statistics.}

Hanushek, Eric A. (1986). "The Economics of Schooling: Production and Efficiency in Public Schools." Journal of Economic Literature 24 (September): 1141-1177.

Hanushek, Eric A. (1996). "School Resources and Student Performance." In Gary Burtless, editor, Does Money Matter? The Effect of School Resources on Student Achievement and Adult Success Washington D.C. : Brookings Institution, 1996, pp. 43-73.

Harlan, Louis R. (1958). Separate and Unequal: Public School Campaigns and Racism in the Southern Seaboard States 1901-1915. Chapel Hill: University of North Carolina Press.

Harmon, Colm, and Ian Walker. 1995. "Estimates of the Economic Return to Schooling in the U.K." American Economic Review 85 (5) : 1278-86.

Heckman, James J. "Lessons from the Bell Curve." Journal of Political Economy 103 (5): 1091-1120.

Heckman, James J., Anne Layne-Farrar, and Petra Todd. "Does Measured School Quality Really Matter? An Examination of the Earnings-Quality Relationship." In Gary Burtless, editor, Does Money Matter? The Effect of School Resources on Student Achievement and Adult Success Washington D.C. : Brookings Institution, 1996, pp. 192-189.

Hedges, L.V. and W. Stock. (1983). "The Effects of Class Size: An Examination of Rival Hypotheses," American Educational Research Journal, 20 (month): 63-65.

Hedges, Larry V., Richard Laine and Rob Greenwald (1994). "Does Money Matter? A Meta-Analysis of Studies of the Effects of Differential School Inputs on Student Outcomes." Education Researcher 23, no. 3 (April) : 5-14. 
Johnson, George and Frank Stafford. (1973). "Social Returns to Quantity and Quality of Schooling." Journal of Human Resources 8 (Spring): 139-155.

Lang, Kevin. (1993). "Ability Bias, Discount Rate Bias and the Return to Education." Unpublished paper, Boston University.

Link, Charles, Edward Ratledge, and Kenneth Lewis. (1980). "The Quality of Education and Cohort Variation in Black-White Earnings Differentials: Reply." American Economic Review 70: 196-203.

Margo, Robert. (1990). Race and Schooling in the South, 1880-1950: An Economic History. Chicago: University of Chicago Press.

McGiverin, J.D., D. Gilman, and C. Tillitski. 1989. "A Meta-analysis of the Relation between Class Size and Achievement." The Elementary School Journal 90 (September) : 47-56.

Morgan, James and Ismail Sirageldin. (1968). "A Note on the Quality Dimension in Education." Journal of Political Economy 76 (September/October): $1069-1077$.

Mosteller, Fredrick. (1995). "The Tennessee Study of Class Size in the Early School Grades." Critical Issues for Children and Youths 5, (Summer/Fall) : 113-127.

Murnane, Frank, John B. Willett, and Frank Levy. (1995). "The Growing Importance of Cognitive Skills in Wage Determination." Review of Economics and Statistics 77, no. 2: 251-266.

Ribich, Thomas I. and James L. Murphy. (1975). "The Economic Returns to Increased Educational Spending." Journal of Human Resources 10 (Spring): 56-77. 
Rizzuto, Ronald and Paul Wachtel. (1980). "Further Evidence on the Returns to School Quality." Journal of Human Resources 15 (Spring): 240-254. 